\title{
Obesity Indicators and Health-related Quality of Life - Insights from a Cohort of Morbidly Obese, Middle-aged South Indian Women
}

\author{
Shobana Ramasamy, ${ }^{1}$ Mini Joseph, ${ }^{2}$ Stephen Amarjeet Jiwanmall, ${ }^{3}$ Dheeraj Kattula, ${ }^{3}$ Munaf Babajan Nandyal, ${ }^{3}$ \\ Vijay Abraham, ${ }^{4}$ Inian Samarasam, ${ }^{4}$ Sandhiya Paravathareddy, ${ }^{2}$ Thomas V Paul, ${ }^{2}$ Simon Rajaratnam, ${ }^{2}$ \\ Nihal Thomas ${ }^{2}$ and Nitin Kapoor ${ }^{2,5}$ \\ 1. Weill Cornell Medicine, New York, NY, USA; 2. Department of Endocrinology, Diabetes and Metabolism, Christian Medical College and \\ Hospital, Vellore, Tamil Nadu, India; 3. Department of Psychiatry, Christian Medical College and Hospital, Vellore, Tamil Nadu, India; \\ 4. Department of Upper Gastrointestinal Surgery, Christian Medical College and Hospital, Vellore, Tamil Nadu, India; \\ 5. Noncommunicable Disease Unit, Melbourne School of Population and Global Health, University of Melbourne, Victoria, Australia
}

DOI: https://doi.org/10.17925/EE.2020.16.2.148

\begin{abstract}
$\mathrm{O}$ bjective: The global prevalence of obesity is increasing and has nearly doubled in the last decade, disproportionately impacting less-developed countries. The aim of this cross-sectional study was to analyse health-related quality of life (HRQOL) in morbidly obese women attending a bariatric clinic in India, and assess potential obesity indicators that can be utilised in under-resourced settings, to better understand HRQOL of individual patients. Methods: Anthropometric measurements were collected, including waist circumference, hip circumference, waist-hip ratio, waist-height ratio and body mass index (BMI). HRQOL was assessed using an obesity-related quality-of-life questionnaire focused on the impact of obesity on physical distress, self-esteem, sexual life and work life. Results: The average BMI of study participants was $39.6 \mathrm{~kg} / \mathrm{m}^{2}$, with an average HRQOL of $40.2 \%$. The strongest correlation was noted between BMI and HRQOL $\left(R^{2}=0.16\right)$. Exploratory analyses demonstrated that patients with higher BMI quartiles had lower scores for physical impact and psychosocial impact, and higher scores for sexual health, comfort with food, and experience with dieting compared to patients in lower quartiles. Conclusion: In South Indian, middle-aged, morbidly obese women, HRQOL is lower than average and is highly correlated with BMI, with different BMI levels having higher impacts in different subcategories, supporting the need for an individualised therapeutic focus for each patient.
\end{abstract}

\section{Keywords}

Morbid obesity, health-related quality of life, middle-aged women, obesity indicators, South Asian phenotype

Disclosures: Shobana Ramasamy, Mini Joseph, Stephen Amarjeet Jiwanmall, Dheeraj Kattula, Munaf Babajan Nandyal, Vijay Abraham, Inian Samarasam, Sandhiya Paravathareddy, Thomas $\vee$ Paul, Simon Rajaratnam, Nihal Thomas and Nitin Kapoor have no financial or non-financial relationships or activities to declare in relation to this article.

Acknowledgements: This study was supported by Vellore Christian Medical College and Weill Cornell Medicine, with immense support from staff attending both institutions. Review Process: Double-blind peer review.

Compliance with Ethics: This study was approved by the Institutional Review Board vide IRB Min No. 10146 dated 22 June 2016. Informed consent was obtained from all individual participants included in the study.

Authorship: The named authors meet the International Committee of Medical Journal Editors (ICMJE) criteria for authorship of this manuscript, take responsibility for the integrity of the work as a whole, and have given final approval for the version to be published. Access: This article is freely accessible at touchENDOCRINOLOGY.com (C) Touch Medical Media 2020

Received: 15 April 2020

Accepted: 1 July 2020

Published Online: 2 October 2020

Citation: European Endocrinology. 2020;16(2):148-51

Corresponding Author: Nitin Kapoor, Department of Endocrinology,

Diabetes and Metabolism, Christian Medical College, Vellore,

Tamil Nadu 632004, India. E: nitin.endocrine@gmail.com

Support: No funding was received in the publication of this article.
The prevalence of obesity has increased exponentially across the world, nearly doubling in the span of a decade. ${ }^{1}$ This is primarily attributed to lifestyle shifts, including diets dominated by hydrogenated fat and animal products, carbohydrate excess and increasingly sedentary lifestyles. The impact of these trends is magnified in developing countries as the resources available to manage the disability and premature deaths related to obesity are limited. In India, wherein $5 \%$ of the population is predicted to be morbidly obese, costs of managing under-nutrition, traditionally considered the dominant social inequality in India, and over-nutrition, will become equal by the year 2025. Furthermore, women are shown to have nearly double the obesity prevalence in Asian countries compared to men. Specifically, in the South Asian population, there has been a $>20 \%$ increase in the prevalence of obesity in women compared to $<15 \%$ in men. ${ }^{3}$ Obesity in the south of the Asian continent shares a common characteristic phenotype across all countries in South Asia, including South India.

Health-related quality of life (HRQOL) is a tool that uniquely assesses several dimensions such as the physical, psychological and sexual health, and dietary experience of patients. ${ }^{4-6}$ Furthermore, HRQOL is an independent risk factor for mortality, particularly among patients with existing metabolic disease.? Considering the short appointment times and elevated patient load among physicians in hospital settings within South Asia, efficient measures of HRQOL, particularly among obese patients, are lacking.

The aim of this study was to analyse HRQOL in morbidly obese women, defined as women with a body mass index (BMI) of $>32.5 \mathrm{~kg} / \mathrm{m}^{2}$, , attending a bariatric clinic in southern India; assess the HRQOL among patients with different grades of obesity; and to ascertain which anthropometric measures of obesity correlate best with HRQOL in these patients. 


\section{Table 1: Baseline characteristics of the study participants}

\begin{tabular}{|c|c|}
\hline Parameter & Value $(n=88)$ \\
\hline Age, years (SD) & $37.3(12.6)$ \\
\hline Geographical location, \% & $\begin{array}{l}\text { Tamilnadu: } 38 \\
\text { Jharkhand: } 19 \\
\text { West Bengal: } 13 \\
\text { Andhra Pradesh: } 8 \\
\text { Kerala: } 4 \\
\text { Other (Bangladesh/UAE): } 18\end{array}$ \\
\hline Education, \% & $\begin{array}{l}<12 \text { th grade standard/high school: } 46 \\
\text { Bachelors: } 18 \\
\text { Masters: } 10 \\
\text { Professional: } 26\end{array}$ \\
\hline Marital status, \% & $\begin{array}{l}\text { Married: } 78 \\
\text { Unmarried: } 22\end{array}$ \\
\hline Number of children, * \% & $\begin{array}{l}\text { Zero: } 21 \\
\text { One: } 10 \\
\text { Two: } 47 \\
\text { Three: } 22\end{array}$ \\
\hline Height, cm (SD) & $156(7.8)$ \\
\hline Weight, kg (SD) & $95.2(17.7)$ \\
\hline Body mass index, $\mathrm{kg} / \mathrm{m}^{2}$ (SD) & $39.6(5.6)$ \\
\hline Waist circumference, cm (SD) & $115(13.7)$ \\
\hline Hip circumference, cm (SD) & $121(11.9)$ \\
\hline
\end{tabular}

* Number of children only included for married women. No unmarried women in the study had children.

$S D=$ standard deviation; $U A E=$ United Arab Emirates

To our knowledge, this study stands as the first study to assess HRQOL in South Asian women and seeks to uniquely determine clinical measures that are applicable for resource-limited and time-constrained settings. We hope that this may be utilised to determine future directions for understanding the aetiology and management of poor HRQOL in South Asian patients.

\section{Methods}

\section{Study design and participants}

We performed a prospective evaluation, conducted in a multidisciplinary bariatric clinic within the Christian Medical College (CMC) of Vellore, dedicated to the treatment of patients with obesity. The bariatric clinic is comprised of medical endocrinologists, bariatric surgeons, psychiatrists and a dietician, located within a South Indian tertiary care hospital. As the clinic is referral based, all participants were referred by their primary-care or specialty-based appointments within the CMC. All consenting participants of this study were women and were required to have a BMI $>32.5 \mathrm{~kg} / \mathrm{m}^{2}$, as per guidelines in South Asian adults. ${ }^{8}$ Patients with a BMI below this and who were below the age of 18 , were excluded. Data were collected over a total of 6 months. This study was approved by the Institutional Review board vide IRB Min No 10146 dated 22 June 2016. Informed consent was obtained from all individual participants included in the study. The Strengthening the Reporting of Observational Studies in Epidemiology (STROBE) reporting guidelines were used while drafting the manuscript. ${ }^{9}$

\section{Measurements}

In our analysis, we evaluated the relationship between HRQOL and anthropometric measures. Anthropometric variables measured included height $(\mathrm{cm})$, weight $(\mathrm{kg}), \mathrm{BMI}\left(\mathrm{kg} / \mathrm{m}^{2}\right)$, waist circumference $(\mathrm{cm})$ and hip circumference $(\mathrm{cm})$. These measures were taken using a standardised tape measure and were measured by the same clinic staff member for all patients.
Table 2: Health-related quality-of-life scores in patient cohort

\begin{tabular}{|l|l|}
\hline HRQOL subcategory & Mean \% (SD) \\
\hline Physical impact & $45(8.23)$ \\
\hline Psychosocial impact & $25(9.12)$ \\
\hline Sexual health & $50(5.66)$ \\
\hline Comfort with food & $45(3.72)$ \\
\hline Diet experience & $40(5.73)$ \\
\hline
\end{tabular}

$H R Q O L=$ health-related quality of life; $S D=$ standard deviation .

Table 3: Associations between anthropometric variables and health-related quality of life

\begin{tabular}{|l|l|l|l|}
\hline Anthropometry & $\mathrm{R}$ & $\mathrm{R}^{2}$ & $\mathrm{p}$ value \\
\hline Waist circumference & -0.171 & 0.029 & 0.181 \\
\hline Hip circumference & -0.381 & 0.143 & 0.002 \\
\hline Waist-height ratio & -0.158 & 0.025 & 0.209 \\
\hline Waist-hip ratio & -0.054 & 0.003 & 0.172 \\
\hline Body mass index & -0.403 & 0.163 & 0.001 \\
\hline
\end{tabular}

$R=$ correlation coefficient; $R^{2}=$ coefficient of determination .

HRQOL was calculated via a detailed, previously-validated questionnaire administered to all patients attending the clinic. ${ }^{4,10} \mathrm{HRQOL}$ was measured using the Quality of Life, Obesity and Dietetics (QOLOD) score, which is a standardised and well-accepted questionnaire, covering the impact of weight on physical activity, psychosocial impact, impact on sex life, comfort with food, and diet experience. The questionnaire consisted of 36 questions divided into four sections, including the impact of obesity on physical distress, self-esteem, sexual health and work-related life. The participants were required to rate each question on a scale of $1-5$, with 1 representing 'always affected' and 5 representing 'never affected'. Thus, a lower final calculated score represented worse HRQOL compared to a higher score. Each individual was evaluated for all four domains of the HRQOL questionnaire.

Mixed methods were employed regarding how the questionnaire was administered. For patients who spoke English as a first language, self-reporting methods were used, and for those who were illiterate or whose primary language was not English, the survey was presented by staff.

For further statistical analysis, each individual score was represented as a percentage, meaning that a score of $36 / 180$ would be $0 \%$ (i.e., HRQOL could not get any worse). To do this conversion, we subtracted 36 from each participant's score and from 180 (the denominator), turning the score into a fraction, which was then converted into a percentage. Individuals who had an HRQOL score (expressed as percentage) $<50 \%$ were considered as having below average HRQOL. We performed an exploratory analysis of BMI as four quartiles and compared the total HRQOL scores between these groups. One-way ANOVA (analysis of variance) was used to compare the mean HRQOL values across the four quartiles of BMI.

\section{Statistical analysis}

Demographic data was analysed with descriptive statistics, such as mean with standard deviation (SD) for the continuous variables, and for the categorical variables, frequency and percentage is provided. 
Table 4a: Demographics of different body mass index quartiles

\begin{tabular}{|c|c|c|c|c|}
\hline Parameter & $\begin{array}{l}\text { Quartile } 1 \\
\left(\leq 35.3 \mathrm{~kg} / \mathrm{m}^{2}\right)\end{array}$ & $\begin{array}{l}\text { Quartile } 2 \\
\left(35.4-39.2 \mathrm{~kg} / \mathrm{m}^{2}\right)\end{array}$ & $\begin{array}{l}\text { Quartile } 3 \\
\left(39.3-42.8 \mathrm{~kg} / \mathrm{m}^{2}\right)\end{array}$ & $\begin{array}{l}\text { Quartile } 4 \\
\left(>42.8 \mathrm{~kg} / \mathrm{m}^{2}\right)\end{array}$ \\
\hline Age, years & $38.2(12.8)$ & $38.5(9.9)$ & $39.1(15.1)$ & $33.3(11.3)$ \\
\hline Body mass index, kg/m² & $33.3(2.1)$ & $37.6(1.2)$ & $41.6(0.9)$ & $46.7(4.8)$ \\
\hline Waist circumference, $\mathrm{cm}$ & $106.7(12.2)$ & $112.0(12.6)$ & $115.8(6.9)$ & $126.1(14.3)$ \\
\hline Hip circumference, cm & $112.9(2.5)$ & $116.7(10.0)$ & $124.3(7.1)$ & $132.3(14.3)$ \\
\hline
\end{tabular}

$N=88 ; n=22$ in each quartile. values presented as mean (SD).

SD $=$ standard deviation

Table 4b: Health-related quality of life and subcategories across body mass index quartiles

\begin{tabular}{|c|c|c|c|c|c|}
\hline Parameter & $\begin{array}{l}\text { Quartile } 1 \\
\left(\leq 35.3 \mathrm{~kg} / \mathrm{m}^{2}\right)\end{array}$ & $\begin{array}{l}\text { Quartile } 2 \\
\left(35.4-39.2 \mathrm{~kg} / \mathrm{m}^{2}\right)\end{array}$ & $\begin{array}{l}\text { Quartile } 3 \\
\left(39.3-42.8 \mathrm{~kg} / \mathrm{m}^{2}\right)\end{array}$ & $\begin{array}{l}\text { Quartile } 4 \\
\left(>42.8 \mathrm{~kg} / \mathrm{m}^{2}\right)\end{array}$ & $p$ value \\
\hline Physical impact & $71.1(16.7)$ & $56.9(15.3)$ & $49.2(21.8)$ & 44.5 (17.4) & $<0.001$ \\
\hline Psychosocial impact & $66.7(24.2)$ & $59.0(17.2)$ & $49.5(22.3)$ & $46.8(19.2)$ & 0.008 \\
\hline Sexual health & $76.1(17.8)$ & $62.0(15.1)$ & $44.3(20.1)$ & $55.0(26.6)$ & $<0.001$ \\
\hline Comfort with food & $64.7(18.7)$ & $57.3(18.0)$ & $42.5(15.0)$ & $52.5(28.0)$ & 0.005 \\
\hline Experience with dieting & $65.7(23.4)$ & $58.4(24.0)$ & $42.3(23.1)$ & $46.8(30.0)$ & 0.011 \\
\hline Total HRQOL & $63.2(21.3)$ & $58.0(14.7)$ & $47.2(17.8)$ & $46.1(20.2)$ & 0.006 \\
\hline
\end{tabular}

Values presented as mean (SD).

$H R Q O L=$ health-related quality of life.

A correlation between different obesity indicators was performed using Pearson and Spearman correlations based on distribution of variables. Coefficient of determination $\left(R^{2}\right)$ was calculated to determine how variance in obesity indicators is explained in the model. Statistical Package for the Social Sciences (SPSS) version 16.0 software (IBM Corp, Armonk, NY, USA) was used for statistical analysis. The threshold of statistical significance was set at $\alpha=0.05$.

\section{Results}

The patient cohort included 88 female patients attending the bariatric clinic. The mean age of the study participants was 37.3 years. Forty-six percent of participants did not pursue education beyond high school. A total of $78 \%$ of the participants were married and $21 \%$ of the married women did not have children (Table 1); none of the unmarried women in the study had children. The average BMl of the study participants was $39.6 \mathrm{~kg} / \mathrm{m}^{2}$.

The average HRQOL score among participants was $40.2 \%$. The individual components have been described in Table 2. A total of $53 / 88(60.2 \%)$ individuals had an HRQOL $<50 \%$. Analysis of potential associations between anthropometric measures and HRQOL focused on five variables: waist circumference, hip circumference, waist-hip ratio, waist-height ratio and BMI. Results demonstrated the strongest correlation between BMI and quality of life ( $R^{2}$ value of 0.163 ), with hip circumference arising as the next strongest correlated variable $\left(R^{2}\right.$ value of 0.143 ; Table 3).

Our exploratory analysis used quartiles to provide a more nuanced and multifaceted understanding of the studied variables (Table $4 a$ and $4 b$ ). Patients in quartiles with higher BMls had increasing waist circumference and hip circumference. In looking at HRQOL categories, patients with higher BMI quartiles had lower scores for physical impact and psychosocial impact, and higher scores for sexual health, comfort with food, and experience with dieting compared with patients in lower quartiles. The individual comparisons of different HRQOL components across increasing quartiles is presented in Table $4 b$.

\section{Discussion}

In our patient cohort, the majority of participants $(53 / 88 ; 60.2 \%)$ scored below average for HRQOL $(<50 \%)$. This held true in both the overall and the subcategory scores, including physical and psychosocial impact, comfort with food, and sexual health. The strongest negative correlation with HRQOL was with BMI in comparison to other anthropometric measures. Despite evidence that overall HRQOL is increasingly poor with increasing BMI, the subcategories responsible for this drop in score in each quartile differ.

HRQOL is a known predictor of future mortality or treatment compliance in a number of populations, though primarily focused on geriatric and terminally ill populations. ${ }^{711}$ Clinically, higher BMI has been significantly correlated with increased health risks including cardiovascular disease, hypertension and diabetes mellitus. ${ }^{12}$ This evidence is particularly striking when considering the population studied. There is growing evidence that South Asian men and women have a higher body fat percentage at lower BMIs compared to their European counterparts, irrespective of age and smoking status. ${ }^{13-15}$ Individuals with a higher body fat percentage and lower $\mathrm{BMI}$ have a significantly increased mortality risk and are more likely to have cardiovascular disease and/or type 2 diabetes. ${ }^{16-19}$ These data were the driving factors for updating the World Health Organization's categories of overweight and obese based on BMI (i.e., rather than a BMI cutoff of $30 \mathrm{~kg} / \mathrm{m}^{2}$ for obese, using a BMl of $25 \mathrm{~kg} / \mathrm{m}^{2}$ in Asian patients). ${ }^{20,21}$ To our knowledge, our study is the first to focus on the intricate topic of HRQOL ina population of obese South Indian women and to look at the subcategories of HRQOL amongst this cohort. These results highlight the need to consider therapeutic interventions that are individualised to a patient's needs based on BMI and their distinct HRQOL profiles in order to be most efficacious.

Though conventionally obesity is considered a disease that affects educated and affluent populations, we found that a large proportion of our subjects had not pursued higher education. ${ }^{22}$ Furthermore, individuals with obesity are often stigmatised among their peers, which may lead to delays in marriage. In our study population, about one-fifth of women 
were not married, despite a mean age of 37 years, which traditionally is a very late age for marriage in the Indian context. ${ }^{23}$

Bariatric clinical practice appears to be moving away from BMI as a measure of obesity with respect to its medical complications, particularly insulin resistance, opting preferably for measures of central adiposity. ${ }^{24,25}$ Moreover, BMI is unable to differentiate the contribution of lean mass against fat mass to the body weight. 24,25 Previous literature is inconsistent with regards to the correlation between BMI and HRQOL in obese individuals, demonstrating both strongly negative and neutral associations when compared to other measures of adiposity. ${ }^{6,26,27}$ Our study makes it evident that BMI, particularly with respect to HRQOL, is not to be ignored. Furthermore, when considering the ease with which BMI can be measured and standardised in a clinical setting compared to central adiposity measures (particularly waist-hip circumference), it appears that BMI is an efficient correlate for HRQOL in morbidly obese South Indian women.
The limitations of this study primarily arose from the small number of patients and lack of a healthy control group to compare the HRQOL. Moreover, since this was a hospital-based study, the results cannot be projected to the general population. Future directions for this research will focus on different therapeutic interventions, including lifestyle changes, medical management or bariatric surgery, and their impact on HRQOL.

Our study demonstrates that in middle-aged South Indian women who are morbidly obese, HRQOL is below average in all areas and is highly correlated with BMI, with different BMI levels having more impact in different subcategories, thus supporting the need for an individualised therapeutic focus for each patient. Furthermore, we recommend using HRQOL as an opportunity to recognise medical and psychiatric comorbidities that may otherwise go unnoticed in a hectic tertiary care setting. $]$
1. Keown OP, Parston $\mathrm{G}$, Patel $\mathrm{H}$, et al. Lessons from eight countries on diffusing innovation in health care. Health Aff (Millwood). 2014;33:1516-22.

2. Ellulu M, Abed Y, Rahmat A, et al. Epidemiology of obesity in developing countries: challenges and prevention. Global Epidemic Obesity. 2014;2:2.

3. Antonisamy B, Raghupathy P, Christopher S, et al. Cohort profile: the 1969-73 Vellore birth cohort study in South India. Int J Epidemiol. 2008:38:663-9.

4. Fontaine KR, Bartlett SJ, Barofsky I. Health-related quality of life among obese persons seeking and not currently seeking treatment. Int J Eat Disord. 2000;27:101-5.

5. Choo J, Turk MT, Jae SY, Choo IH. Factors associated with health-related quality of life among overweight and obese Korean women. Women Health. 2015;55:152-66.

6. McLaughlin L, Hinyard $\mathrm{L}$. The relationship between health-related quality of life and body mass index. West $J$ Nurs Res. 2014;36:989-1001.

7. Brown DS, Thompson WW, Zack MM, et al. Associations between health-related quality of life and mortality in older adults. Prev SCi. 2015;16:21-30.

8. Behl S, Misra A. Management of obesity in adult Asian Indians. Indian Heart J. 2017:69:539-44.

9. Vandenbroucke JP, Von Elm E, Altman DG, et al. Strengthening the Reporting of Observational Studies in Epidemiology (STROBE): explanation and elaboration. Ann Intern Med. 2007;147:W163-94.

10. Ziegler O, Filipecki J, Girod I, Guillemin F. Development and validation of a French obesity-specific quality of life questionnaire: Quality of Life, Obesity and Dietetics (QOLOD) rating scale. Diabetes Metab. 2005;31:273-83.
11. Rask-Andersen A, Leander M, Janson C. A long-time follow-up of mortality, asthma, and health-related quality of life in an elderly. Eur Respir J. 2016;48:PA4220.

12. Bays HE, Chapman R, Grandy S, Group SI. The relationship of body mass index to diabetes mellitus, hypertension and dyslipidaemia: comparison of data from two national surveys. dysilipidaemia. comparison of

13. Lear SA, Humphries KH, Kohli S, Birmingham CL. The use of BM and waist circumference as surrogates of body fat differs by ethnicity. Obesity. 2007:15:2817-24.

14. Kuo J-F, Hsieh Y-T, Mao I-C, et al. The association between body mass index and all-cause mortality in patients with type 2 diabetes mellitus: a 5.5-year prospective analysis. Medicine (Baltimore). 2015;94:e1398.

15. Kapoor N, Furler J, Paul TV, et al. Normal weight obesity: an underrecognized problem in individuals of South Asian descent. Clin Ther. 2019;41:1638-42.

16. Kapoor N, Furler J, Paul TV, et al. The BMI-adiposity conundrum in South Asian populations: need for further research. J Biosoc SCi. 2019;51:619-21.

17. Kapoor N, Furler J, Paul TV, et al. Ethnicity-specific cut-offs that predict co-morbidities: the way forward for optimal utility of predict co-morbidities. the way forward for op

18. Kapoor $\mathrm{N}$, Lotfaliany $\mathrm{M}$, Sathish $\mathrm{T}$, et al. Obesity indicators that best predict type 2 diabetes in an Indian population: insights from the Kerala Diabetes Prevention Program. J Nutr Sci. 2020;9:e15.

19. Kapoor N, Lotfaliany M, Sathish T, et al. Prevalence of normal weight obesity and its associated cardio-metabolic risk factors - Results from the baseline data of the Kerala Diabetes Prevention Program (KDPP). PLoS One. 2020;15:e0237974.
20. Jih J, Mukherjea A, Vittinghoff E, et al. Using appropriate body mass index cut points for overweight and obesity among Asian Americans. Prev Med. 2014;65:1-6.

21. Misra A. Ethnic-specific criteria for classification of body mass index: a perspective for Asian Indians and American Diabetes Association Position Statement. Diabetes Technol Ther. 2015:17:667-71

22. Endalifer ML, Diress G. Epidemiology, predisposing factors, biomarkers, and prevention mechanism of obesity: A systematic review. J Obes. 2020;2020:6134362.

23. Rubino F, Puhl RM, Cummings DE, et al. Joint international consensus statement for ending stigma of obesity. Nat Med. 2020;26:485-97

24. Nazare J-A, Smith JD, Borel A-L, et al. Ethnic influences on the relations between abdominal subcutaneous and viscera adiposity, liver fat, and cardiometabolic risk profile: the International Study of Prediction of Intra-Abdominal Adiposity and Its Relationship With Cardiometabolic Risk/Intra-Abdomina Adiposity. Am J Clin Nutr. 2012;96:714-26.

25. Riserus U, De Faire U, Berglund L, Hellénius M-L. Sagittal abdominal diameter as a screening tool in clinical research:

26. Taylor AE Ebrahim S, Ben-Shlomo Y et al. Comparison of the associations of body mass index and measures of central associations or body mass index and measures of centraladiposity and fat mass with coronary heart disease, diabetes, and all-cause mortality: a study using data from 4 UK cohorts Am J Clin Nutr. 2010;91:547-56.

27. Park S. Pathways linking obesity to health-related quality of life. Qual Life Res. 2017;26:2209-18. 